\title{
Elementos estructurales del derecho a la verdad'
}

\section{Luis Andrés Fajardo Arturo²}

andres.fajardo@usa.edu.co

\begin{abstract}
Artículo de la Revista Civilizar Ciencias Sociales
y Humanas de la Universidad Sergio Arboleda ${ }^{3}$
\end{abstract}

\footnotetext{
${ }^{1}$ Artículo resultado de investigación. Grupo de las Casas. Escuela de Derecho de la Universidad Sergio Arboleda.

${ }^{2}$ Abogado, magíster en Derecho Internacional, magíster en Derecho con énfasis en Derecho Administrativo, investigador del Grupo De las Casas, director del Departamento de Derechos Humanos de la Universidad Sergio Arboleda. Agradecimiento a Libeth María Maya Galeano del semillero de apoyo. Correo electrónico: andres. fajardo@usa.edu.co

${ }^{3}$ Fuente original en Fajardo Arturo, Luis A. (2012). Elementos estructurales del derecho a la verdad. Civilizar Ciencias Sociales y Humanas, 12(22), 15-34. Agradecimientos especiales a Luis Andrés Fajardo Arturo, así como Yadira Caballero directora de publicaciones de la Universidad Sergio Arboleda, por permitirnos publicar este artículo tan relevante para la temática del número. Esta nota al fue agregada por el Equipo Editorial de la revista Trans-pasando Fronteras.
} 


\section{Resumen}

Este artículo se refiere específicamente al estado actual de la discusión sobre la estructura jurídica fundamental del derecho a la verdad, sus dimensiones y su grado de juridicidad y da cuenta de los primeros resultados obtenidos sobre la evaluación de los modelos de paz adoptados en Colombia, a la luz de los estándares y ejemplos internacionales.

Palabras clave: Justicia; Reparación; Víctimas; Comisiones de la verdad. 


\title{
Structural elements of the right to the truth
}

\begin{abstract}
This article refers specifically to the current state of the discussion on the basic legal structure of the right to truth, its size and degree of legality and reports initial results on the evaluation of the models adopted for peace in Colombia, in light of the international standards and practices.
\end{abstract}

Keywords: Justice; Redress; Victims; Truth Commissions.

\section{Introducción}

La verdad tiene una relación íntima con el derecho y la justicia, tanto como fundamento filosófico o como un requisito condicionante de la legitimidad de los fallos, la verdad es un elemento que precede la aplicación del derecho y es indispensable para hacer justicia, por lo que justamente es en la búsqueda de la verdad (podría hablarse de verdad judicial pero, finalmente, el derecho siempre busca la verdad real), en especial el derecho penal, tal como lo sostiene Naqvi (2006).

Pero la verdad que toca al derecho no es únicamente aquella que pueda generar elementos relevantes para la aplicación de las normas. El derecho internacional de la persona humana (derecho internacional de los derechos humanos y DIH), a partir de los convenios 
de Ginebra, fue desarrollando el concepto del derecho a saber la verdad, como un derecho individual en cabeza de los familiares de las víctimas a conocer el paradero y la suerte de sus familiares en un conflicto armado (Primer Convenio de Ginebra, art. 32, 1949).

Con el pasar de las décadas, este derecho individual fue mutando en un concepto mucho más amplio e interdisciplinario. Se trata del derecho de toda la sociedad a conocer la verdad sobre las causas, modos y consecuencias de un conflicto armado, en especial cuando se trata de hechos que generan graves y sistemáticas violaciones de derechos humanos y, particularmente, se exige para que los procesos de transición entre el conflicto y la estabilidad sociopolítica respondan a una necesidad social por conocer su historia.

El derecho a la verdad, entendido tal, como se describe en la segunda dimensión, se estatuye como una necesidad de la sociedad para construir su futuro sobre los cimientos de la verdad, que son los únicos que pueden soportar la construcción de una sociedad pacífica. El derecho a conocer la verdad implica cerrar un capítulo, aprendiendo del mismo para no repetirlo, es una estrategia de sustentabilidad de la paz, pues como se ha visto a lo largo de la historia, las guerras tienden a repetirse cuando no quedan suficientemente cerradas. Mientras subsista el silencio sobre lo sucedido, mientras no se encuentre la verdad, la posibilidad de creer que se ha cerrado un ciclo de violencia es nula, el conflicto continúa hasta que se sabe la verdad tanto judicial como histórica.

Respecto de este concepto de verdad, el derecho internacional ha regulado muy poco; en general, parecería que el derecho a la verdad pertenece exclusivamente al mundo del soft law (o derecho progresivo, no vinculante jurídicamente) y son muy pocas las obligaciones jurídicas derivadas del hard law (tratados, costumbres y, en general, normas internacionales vigentes) respecto a este derecho. 
Pero si la normatividad es escasa, la realidad es abundante. Los ejemplos de comisiones de la verdad en el mundo son innumerables, algunas de ellas representar verdaderos ejemplos para la superación de un conflicto; otras, quizás menos afortunadas en cuanto a sus resultados, y todas ellas, con enormes diferencias en cuanto a su formación, metodología y duración, coherentes con las diferencias de los conflictos a que se han referido.

Según informes de la organización Amnistía Internacional, en el mundo se cuentan al menos 34 grandes comisiones de la verdad (http://www.amnesty.org/es/international-justice/issues/truthcommissions) y tan solo en Latinoamérica, las comisiones de Chile, Perú, Argentina, Uruguay, Guatemala y El Salvador representan importantes esfuerzos por superar gravísimas situaciones de vulneración de derechos humanos. Incluso independientemente de la existencia de un conflicto armado, los países del continente americano han creado comisiones de la verdad para enfrentar situaciones coyunturales cuya importancia social ha meritado generar una reflexión, tal como sucedió en Ecuador o Bolivia. En Colombia, a pesar de la importancia del conflicto en que se ha desarrollado gran parte de la historia del último siglo y, muy a pesar de la necesidad que tiene la sociedad de conocer a fondo lo que sucedió, no ha habido un esfuerzo serio por investigar, construir y divulgar un relato consensuado y profundo sobre los hechos causantes de graves violaciones de derechos humanos y del DIH. Planteado de forma sucinta, el problema jurídico del cual parte la investigación que da pie a esta ponencia se concreta en la siguiente pregunta: ¿actualmente Colombia cumple de forma adecuada con sus obligaciones en cuanto al derecho a la verdad?

Este problema general implica obviamente el conocimiento previo de distintos problemas específicos, de los cuales, los más rel- 
evantes según el abordaje escogido son: ¿es la verdad un derecho humano?, ¿en cabeza de quién radica dicho derecho?, ¿qué obligaciones genera y con base en qué cuerpo normativo?, ¿qué esfuerzos ha realizado Colombia con respecto a la verdad histórica?, ¿qué tan adecuados son dichos esfuerzos en relación con los estándares internacionales en la materia?

La investigación de la que surge este primer resultado tiene como objetivo establecer, con total claridad, el espectro de obligaciones que genera el derecho a la verdad y, con base en él, evaluar los esfuerzos existentes en Colombia para finalmente proponer lineamientos claros respecto a la necesidad, viabilidad y modelo a seguir en la construcción de la verdad histórica del país. Los objetivos específicos son los de contribuir a la generación de conocimiento respecto al derecho a la verdad, en particular acerca de la discusión doctrinaria, su cuerpo normativo y la interpretación jurisprudencial internacional y nacional. En segundo lugar, se trata de analizar las estrategias nacionales en cuanto a la verdad bajo la lupa del derecho existente en la materia para analizar las falencias de los modelos adoptados en Colombia.

En cuanto al texto aquí presentado, el objetivo final es generar una visión clara de la naturaleza del derecho a la verdad y las obligaciones que genera a fin de poder evaluar la coherencia y adecuación de las medidas que Colombia está tomando en la materia.

\section{Metodología}

El diseño metodológico adoptado se divide fundamentalmente en tres etapas. La primera etapa, destinada a la determinación del concepto jurídico del "derecho a la verdad", se desarrolló a través 
de la construcción del corpus iuris relativo a la materia, el análisis del estado del arte sobre el tema y, posteriormente, la construcción y determinación de los lineamientos jurisprudenciales, tanto a nivel interamericano como a nivel nacional.

Para esta etapa, el semillero de investigación que acompañó el proyecto se encargó de adelantar la recolección de normas, y textos. Se distribuyó el trabajo de análisis de la doctrina a través de la búsqueda sistemática en las bibliotecas de Bogotá. La indagación se dividió en distintas etapas, en primer lugar, a partir del idioma, la nacionalidad de los autores y, finalmente, los asuntos tratados, buscando ir de lo más general a lo más particular, con hallazgos muy importantes en la materia a nivel nacional e incluso subregional y con una preponderancia en el idioma inglés.

Los textos encontrados fueron analizados enfocándose particularmente en los textos relativos a la verdad como derecho, buscando establecer el estado de la discusión al respecto. Las conclusiones obtenidas fueron extraídas, enumeradas y clasificadas, de forma que sea posible distinguir los principales aportes, las posiciones y contradicciones respecto a cada autor o grupo de autores.

En cuanto a los aspectos jurídicos y jurisprudenciales, el investigador principal se dedicó a buscar las normas relacionadas con la verdad y a construir un corpus iuris aplicable, a partir, fundamentalmente, de los pronunciamientos de los organismos internacionales de derechos humanos. Los hallazgos fueron contrastados y ampliados gracias a los instrumentos traídos a colación por la jurisprudencia y la doctrina. Los resultados en materia normativa resultaron ser muy escasos 


\section{Resultados}

¿Qué es el derecho a la verdad?

Hablar del derecho a la verdad, (o a conocer la verdad) implica concentrar en la víctima los esfuerzos por restablecer el orden y la tranquilidad en una sociedad que está saliendo o ha salido de una etapa de violencia. En ese sentido el derecho a la verdad se ha constituido a lo largo de los años en el eje principal de la reconciliación y la paz. Según Hernández (2006) "desde la perspectiva de las víctimas de la violencia, la reconciliación equivale a derecho a la verdad, superación de impunidad y reparación integral".

Se trata de un privilegio que surge de situaciones de violencia generalizada, y que se fundamenta en la importancia de la verdad para cerrar un ciclo de violencia y transitar a una etapa de paz. González Salzberg (s.f. ) define: "(...) el derecho a la verdad como el derecho que asiste a las víctimas - directas e indirectas- de graves violaciones al DIH o al DIDH, como también a la sociedad en su conjunto, a conocer lo verdaderamente ocurrido en tales situaciones".

La discusión en torno a este pretendido derecho es si verdaderamente se trata de una institución jurídica, o si en realidad se trata de una pretensión social sin respaldo normativo. Sobre el punto, Rincón Covelli (2005) afirma que conocer o saber la verdad es, en el sistema normativo de los derechos humanos, un derecho. Esto significa, entre otras cosas, que un Estado puede llegar a ser (declarado) responsable de violar (por acción o por omisión) el derecho de las personas a la verdad o a saber lo que ocurrió.

En ese sentido, Vivian Newman (2009) propone una definición del derecho a la verdad según la cual: "Es el derecho individual y colectivo a saber los hechos, las circunstancias, las causas, las con- 
secuencias, los responsables y las víctimas de las violaciones de los derechos humanos y el derecho internacional humanitario".

Por su parte, refiriéndose a la autonomía o independencia de este derecho, Correa (2007) expresa que el derecho a la verdad es el derecho al esclarecimiento de la misma y a los mecanismos de reparación. Se trata de una modalidad del derecho a recibir informaciones y en este contexto señala que en teoría existen tres modelos institucionales de verdad en los procesos de paz a saber: la verdad judicial en la que el juez decide; la verdad extrajudicial e institucional, que es la establecida por una comisión de la verdad, y la verdad extrajudicial no institucional, que es la que surge las publicaciones académicas y de prensa. El derecho a la verdad estaría satisfecho a través de todos los medios y no de uno solo de ellos.

Si bien el desarrollo normativo ha sido bastante escaso, la doctrina ha sido prolífica y profunda en el análisis de este derecho. Así, en las Naciones Unidas el derecho a la verdad según el Comité de Derechos Humanos de la ONU (s.f.)

(...) Es un derecho tanto colectivo como individual. Toda víctima tiene derecho a conocer la verdad sobre las violaciones que le afectan, pero la verdad debe comunicarse también a la sociedad como una salvaguardia fundamental contra la repetición de tales violaciones, según se indica en el principio 2 del Conjunto de principios para la protección y la promoción de los derechos humanos mediante la lucha contra la impunidad.

Por su parte, en la OEA, el Sistema Interamericano de Derechos Humanos se ha referido en distintas oportunidades a este derecho. La Comisión Interamericana de Derechos Humanos ha definido al respecto: 
El derecho a la verdad es de carácter colectivo que permite a la sociedad tener acceso a información esencial para el desarrollo de los sistemas democráticos y un derecho particular para los familiares de las víctimas, que permite una forma de reparación, en particular, en los casos de aplicación de leyes de amnistía (CIDH, Caso Bámaca vs. Guatemala, 2002).

En esta definición no se hace énfasis en las víctimas, pero se entiende de manera tácita que al ser las primeras afectadas en sus derechos son las principales titulares cuando, evidentemente, no se ha atentado contra su vida ya que, como señala Rincón (2005), "la verdad para las víctimas las dignifica y convierte la verdad de la víctima en la verdad de la sociedad. La víctima ayuda a construir la verdad".

Además, en el último inciso de la definición previamente señalada, frente a los casos de amnistía donde no existe acción contra los responsables, "el desconocimiento de la verdad conlleva a que el Estado imponga una ley de 'perdón y olvido' bajo la cual se hace a un lado la memoria histórica, se desconoce la verdad de las víctimas y se incrementa la impunidad" (CNM, 2008); se advierte en dicho punto la reparación que constituirá la verdad frente a estas leyes de perdón y olvido, que se consagra en el resarcimiento a las víctimas más que material, moral. "Esta facultad o prerrogativa a obtener la verdad tiene una naturaleza esencialmente moral" (Salgado, salvamento de voto caso Bámaca Velásquez vs. Perú, 2002).

Lo difícil de estas definiciones es que se quedan cortas ante los elementos estructurales del derecho a la verdad. En primer lugar, es necesario identificar en qué consiste el derecho, o en otras palabras, cuál es el contenido de la obligación que surge del mismo; 
en segundo lugar, se deben identificar claramente los titulares, tanto de derechos como de obligaciones, y en último lugar, las condiciones adicionales que sean necesarias para su exigibilidad.

Así pues, el derecho a la verdad no es un privilegio inherente que se pueda exigir en todo tiempo y circunstancia por todo ser humano. Es un derecho que si bien está en potencia en todo ser humano, solo se activa en el momento en que se configura una situación de violencia que implique violaciones graves a los derechos humanos (condición del derecho). En esas circunstancias se activan dos tipos de titulares: por una parte, las víctimas o sus familiares (primer titular) tienen derecho a conocer la suerte de sus parientes y el contexto de los hechos -entendiendo por contexto las causas, objetivos, consecuencias de la violencia, modus operandi y responsables de la misma- y a su vez, la sociedad tiene el derecho y deber de conocer lo sucedido.

Si bien los titulares del derecho son múltiples, los de la obligación lo son aún más: por una parte, el Estado, que está obligado a adelantar todas las tareas para contribuir a esclarecer lo sucedido a través de las herramientas que permitan llegar a la verdad judicial y extrajudicial sobre los hechos.

Por otra parte, los autores de los hechos, cuando no tratándose del Estado se constituyen como un aparato organizado de poder con capacidad de respetar el DIH, y por lo tanto deben contribuir a esclarecer los hechos como parte de sus obligaciones con este conjunto de normas, y por último la sociedad, que no solo es titular del derecho a saber, sino que está obligada a conocer. Esta última resulta quizá la más compleja de las titularidades, pero como se verá más adelante, representa un punto nodal en la realización del derecho y el logro del objetivo, que es buscar la paz y reconciliación. 
En tal sentido, se puede definir el Ilamado "derecho a la verdad" como el derecho que surge a las víctimas, sus familiares y a la sociedad en general, en los casos en que han sucedido graves violaciones de derechos humanos, y en virtud del cual, el Estado tiene la obligación de adelantar las medidas para lograr establecer la verdad sobre los hechos, los grupos organizados que hayan participado de la violencia deben contribuir a establecer la verdad, y la sociedad en su conjunto tiene el deber de conocer lo sucedido.

\section{Origen del derecho a la verdad}

Según relata el alto comisionado de las Naciones Unidas para los Derechos Humanos (2006) en su 'Estudio sobre derecho a la verdad', el derecho a la verdad tiene su origen más remoto los Tratados de Ginebra sobre Derecho Internacional Humanitario, cuando por primera vez, en el artículo 32 del Primer Convenio se estipuló que los familiares de las víctimas y de los prisioneros tenían derecho a saber la verdad sobre lo sucedido.

En efecto, en la década de los años setenta, con motivo del inicio de una práctica sistemática de desapariciones forzadas, organizaciones internacionales como el Grupo de Trabajo ad hoc encargado de estudiar la situación de los derechos humanos en Chile, el Grupo de Trabajo sobre las Desapariciones Forzadas o Involuntarias y la Comisión Interamericana de Derechos Humanos iniciaron un estudio serio sobre el tema, llegando a la conclusión común de que el fundamento jurídico del derecho a la verdad se encontraba en los artículos 32 y 33 del Protocolo I de los Convenios de Ginebra de 1949, ya que en ellos las víctimas hacían énfasis en la necesidad de saber: 
Artículo 32: en la aplicación de la presente sección, las actividades de las altas partes contratantes, de las partes en conflicto y de las organizaciones humanitarias internacionales mencionadas en los convenios y en el presente protocolo deberán estar motivadas ante todo por el derecho que asiste a las familias de conocer la suerte de sus miembros (Protocolo adicional a los Convenios de Ginebra, art. 32, 1949).

Está antigua regla del DIH fue utilizada inicialmente en materia de derechos humanos como referencia al derecho a la verdad, en el marco de las desapariciones forzadas, como el derecho que tenían los familiares de las víctimas a conocer el paradero de sus familiares. Al respecto, la CICR (2005) estableció que:

(...) El derecho a la verdad era una norma del derecho internacional consuetudinario aplicable tanto a los conflictos armados internacionales como a los internos, de modo que cada parte en el conflicto debía tomar todas las medidas factibles para conocer el paradero de las personas presuntamente desaparecidas a raíz de un conflicto armado y debían comunicar a sus familiares todo dato de que dispusieran acerca de su suerte.

Sin embargo, el derecho a la verdad no se limitó a esta faceta, sino que con el paso de las décadas fue abarcando otras violaciones graves de derechos humanos como la ejecución extrajudicial y la tortura. Fundamentalmente, es a finales de los años ochenta y en especial en la década de los noventa en que el derecho internacional se mete de lleno en la determinación de los derechos de las víctimas 
y en particular del derecho a la verdad. Así es como se desarrolla el documento que contiene los principios de estos derechos y la lucha contra la impunidad de Louis Joinet (1997), cuyo origen y desarrollo comienza en 1991 y termina en 1997, para luego ser actualizado en 2005. Por su parte, en la Corte Interamericana de Derechos Humanos el derecho a la verdad apareció someramente en la jurisprudencia temprana desde el caso Velásquez Rodríguez vs. Honduras (1987) y se fue consolidando gracias al informe Joinet, en casos como Barrios Altos vs. Perú (2001), en que la Corte estableció que las amnistías obstaculizan las investigaciones y por lo tanto pueden llegar a ser incompatibles con los derechos de las víctimas ${ }^{4}$, o casos mucho más recientes como el caso Manuel Cepeda Vargas vs. Colombia (2010), en que la Corte se refirió al derecho a la verdad de la sociedad.

El surgimiento de las "comisiones de verdad" resulta muy interesante para el derecho internacional, pues a ellas se les encarga la misión de investigar sobre las transgresiones de los derechos humanos a fin de identificar el sujeto que las realizó. Son un organismo de investigación autónomo centrado en las víctimas, establecido ad hoc en un Estado (y autorizado por el mismo Estado; Freeman, 2007).

Esas comisiones, que son órganos de investigación oficialmente autorizados, de carácter temporal y no judicial, disponen de un plazo relativamente corto para tomar declaraciones, realizar investigaciones y estudios y celebrar audiencias públicas antes de ultimar su labor con la publicación de un informe. Aunque

\footnotetext{
${ }^{4}$ Dice la Corte son inadmisibles las disposiciones de amnistía, las disposiciones de prescripción y el establecimiento de excluyentes de responsabilidad que pretendan impedir la investigación y sanción de los responsables de las violaciones graves de los derechos humanos tales como la tortura, las ejecuciones sumarias, extralegales o arbitrarias y las desapariciones forzadas, todas ellas prohibidas por contravenir derechos inderogables reconocidos por el Derecho Internacional de los Derechos Humanos".
} 
las comisiones de la verdad no son un sustituto de la acción judicial, sí ofrecen cierta posibilidad de explicar el pasado, por lo que han sido particularmente útiles en aquellas situaciones en las que emprender el enjuiciamiento por crímenes masivos era imposible o poco probable, fuera por falta de capacidad del sistema judicial o por una amnistía de hecho o de derecho (Hayner, 2006).

En general, los actos jurídicos por los que se crean esas comisiones se basan en la necesidad de las víctimas, sus familiares y la sociedad en general de conocer la verdad sobre lo sucedido; facilitar el proceso de reconciliación; contribuir a la lucha contra la impunidad y reinstaurar o fortalecer la democracia y el Estado de derecho (S. A, abril de 1990).

De esta forma se va estructurando la teoría de la verdad, pues señala los eventos en los cuales nace el derecho de conocer y la creación de un órgano competente en cuanto a la investigación de esa verdad.

En el año 2005, el derecho a la verdad logra gran reconocimiento, tanto para las víctimas como familiares, como se citó anteriormente, en especial porque, habida cuenta de los avances que venían sucediendo en la materia, la Comisión de Derechos Humanos de la ONU solicita y recibe la actualización del conjunto de principios para la protección y la promoción de los derechos humanos, para la lucha contra la impunidad de M. Joinet (1997). En tal sentido, el trabajo realizado por la experta independiente doctora Diane Orentlicher se encarga de poner al día el conjunto de principios y desarrollar ampliamente el capítulo de derecho a la verdad.

Este último, según el texto de los principios actualizados por Diane Orentlicher (E/ CN.4/2005/102/Add.1 Consejo Económico y Social Naciones Unidas, Promoción y Protección de los Derechos 
Humanos), se divide en una serie de principios que establecen sus alcances e implicaciones, proporcionando los pilares sobre los cuales se edifica la teoría del derecho a la verdad. Vale la pena destacar que los principios 2 y 3 establecen las dimensiones específicas del derecho a la verdad: el derecho inalienable a la verdad (como un privilegio de los familiares de las víctimas) y el deber de saber (como un derecho-deber de la sociedad).

Más adelante, la Resolución 2005/66 de la Comisión de Derechos Humanos solicita al alto comisionado de las Naciones Unidas para los Derechos Humanos "un estudio sobre el derecho a la verdad en el que figurase información sobre los fundamentos, el alcance y el significado de ese derecho en el derecho internacional, así como las mejores prácticas y recomendaciones para asegurar el ejercicio efectivo de ese derecho, en particular las medidas legislativas, administrativas o de otra índole que puedan adoptarse al respecto, teniendo en cuenta la opinión de los Estados y las organizaciones intergubernamentales y no gubernamentales pertinentes, para examinarlo en su $62^{\circ}$ período de sesiones" (Comisión de Derechos Humanos, 2005).

El informe se presenta a la Comisión en su $62^{\circ}$ período de sesiones y aparece radicado con el número E/CN.4/2006/91, del 9 de enero de 2006. En dicho estudio se estipula la base jurídica, naturaleza e historia del derecho a la verdad, destacando la importancia de las comisiones de la verdad en la materia. Un resumen de las ideas principales del estudio se plantea a continuación:

La verdad tiene como objetivo fundamental luchar contra la impunidad, es decir, sancionar todas estas conductas que atentan gravemente contra el Derecho Internacional Humanitario y que, por falta de conocimiento de los hechos, no se sancionan debida- 
mente, pues el agente queda libre de toda responsabilidad penal, civil o administrativa dependiendo del caso.

Para evitar esta impunidad, que se estaba convirtiendo en parte de la cotidianidad, y darles eficacia e impulso a los procedimientos que tenían como objetivo la búsqueda de la verdad, se establecieron unos organismos de carácter no judicial, denominados comisiones de verdad. Estas brindan apoyo especial en la labor investigativa, gozan de plenas competencias al momento de ejecutar sus funciones, que debe tener como característica principal la imparcialidad. El fin de este órgano es encontrar esa información exenta de vicios para darle publicidad y prevenir la ejecución de futuros comportamientos violatorios.

\section{Estructura jurídica del derecho a la verdad}

En Colombia, particularmente, la doctrina tiende a aceptar sin mayor discusión la naturaleza jurídica del derecho a la verdad como un derecho vigente, sin adentrarse en la discusión de la naturaleza formal del mismo. Para Rincón (2010) el sustento jurídico está en los principios de la ONU, especialmente gracias al reconocimiento jurisprudencial que la CRIDH ha venido haciendo a lo largo de sus sentencias. Por otra parte, para Uprimny y Saffón (2009, citado en Gamboa, s.f.) el fundamento internacional es la jurisprudencia interamericana, que al ser la interpretación autorizada de un tratado ratificado por Colombia se convierte en una norma de valor constitucional vía bloque de legitimidad.

Lo cierto es que, como bien lo expone Naqvi (2006) el "derecho a la verdad" no se encuentra refrendado per se en ningún instrumento jurídico internacional, ni a nivel universal ni en sistemas 
regionales. No existe actualmente ningún instrumento de hard law que consagre una obligación convencional sobre derecho a la verdad a excepción de la referencia al derecho a los familiares de las víctimas del convenio de Ginebra.

Sin embargo, las fuentes del derecho internacional público son más amplias que los tratados, tal como lo determina el mismo artículo 38 del Estatuto de la Corte Internacional de Justicia (1948) por lo que se hace necesario interrogarse sobre su naturaleza consuetudinaria o de principio legal. Respecto de la primera, resulta interesante revisar que pareciera existir una práctica general y reiterada de los países a utilizar sistemas de investigación y construcción de la verdad histórica luego de un episodio de graves violaciones de derechos humanos.

El conjunto de principios actualizados sobre los derechos de las víctimas en la lucha contra la impunidad tiene como base el documento Joinet y se adecúa a las necesidades y experiencias del siglo XXI, pero no tiene valor vinculatorio.

Tampoco es posible determinar sin discusión que, por la existencia generalizada de comisiones de la verdad en el mundo, puede hablarse formalmente de un derecho consuetudinario. La discusión doctrinaria en la materia se fundamenta principalmente en la exigencia de ciertos elementos para determinar la existencia de una costumbre internacional en lo concerniente a derechos humanos. El profesor Meron (1989) señala que como mínimo, tanto la definición de la norma básica como los rasgos generales de la misma deben haber sido generalmente aceptados. En ello discute la doctrina, con opositores a su estructura como Méndez (1998) o Naqvi (2006), que sostienen que se trata de un derecho de naturaleza diferente, o bien surtido de tratados o bien por fuera del derecho. 
Un nutrido sector de la doctrina ha afirmado que el derecho a la verdad ha alcanzado la categoría de norma de derecho internacional consuetudinario, y que del análisis del derecho internacional humanitario consuetudinario a cargo del Comité Internacional de la Cruz Roja lo incluye en referencia personas desaparecidas como una costumbre aplicable tanto a conflictos nacionales como internacionales. Sin embargo, se debe hacer examen del cumplimiento de ciertos requisitos exigidos en el Derecho Internacional de los Derechos Humanos: un elemento material basado en la práctica reiterada (usus) y un elemento psicológico, que es la obligatoriedad jurídica de los comportamientos que la integran (opinio iuris); para la aprobación de dichos requisitos la doctrina ha establecido tres clases de indicadores, a saber: i) Grado en que el derecho se reconoce en otros tratados e instrumentos, ii) medidas adoptadas internamente por los Estados para adecuarse a la respectiva regla y iii) Existencia de cláusulas restrictivas contra esa práctica.

En cuanto al primer requisito, como ya se ha mencionado anteriormente aparte del Convenio I de de Ginebra, que no es suficiente al limitarse a casos de personas desaparecidas, no existe actualmente un tratado o algún documento que dote de suficiente autonomía el derecho internacional de la verdad y deje de ser visto como un articulado en conexión a la violación de otro derecho fundamental. Pero con base en otros instrumentos cabe resaltar que el derecho a la verdad ha sido citado, mencionado, referenciado, definido y exaltado como un derecho por sí mismo y como una modalidad de prevención frente a otros delitos que se ven coligados con el mismo; como prueba de lo anterior, el Comité de Derechos Humanos, así como el Tribunal Europeo de Derechos Humanos, reconocieron el derecho a saber y conocer como un modo de prevenir la tortura psicológica de los familiares de aquellos que han sido víctimas (PIDCP, arts. 7 y 23, s.f.; CDN, 
art. 8, s.f.). La Comisión y la Corte Interamericana de Derechos Humanos han reconocido de igual forma el derecho a saber como un recurso directo y como un requisito para la garantía de otros derechos fundamentales y prohibición de delitos tales como la tortura, ejecuciones extrajudiciales y en general todas aquellas conductas tendientes a poner en peligro los derechos fundamentales. Por otra parte, encontramos las resoluciones que ha emitido el Consejo Económico y Social y la Asamblea General de las Naciones Unidas, y de igual forma las declaraciones del secretario general y del alto comisionado para los Derechos Humanos son una prueba sólida e irrefutable del cumplimiento de este requisito de la verdad como derecho consuetudinario.

En ese sentido, Leandro Despouy, relator especial sobre los derechos humanos y los estados de excepción (E/CN.4/ Sub.2/1997/21), en su $8^{\circ}$ informe anual: documento de la ONU E/ CN.4/Sub.2/1995/29 Corr. 1, sostiene que en la reunión de expertos concluyeron que el derecho a la verdad ha alcanzado la categoría de norma del derecho internacional consuetudinario.

Con base en el segundo requisito propuesto, la confirmación de la práctica reiterada, uniforme y pública en el derecho nacional es una señal que indica el reconocimiento de conciencia que tienen los pueblos de que una práctica es creadora de derecho. En el ámbito de la verdad se pueden distinguir alrededor de unas 32 comisiones de verdad (Amnistía Internacional, http://www.amnesty.org/es/international-justice/issues/truth-commissions) que han surgido en África, América y Europa, en países que han presentado conflictos armados con graves violaciones de derechos humanos.

Respecto de Colombia en particular, no cabe duda de su opinio juris en la materia, puesto que en la respuesta que se dio sobre la nota verbal del 15 de julio de 2005 de Oacnudh, la cual necesitaba 
recolectar información sobre el derecho a la verdad en resolución 2005/66, con respecto a esto, Colombia afirmó que este se trataba de un derecho de carácter autónomo en el ámbito internacional. De igual modo la Corte Constitucional de Colombia, en sentencia T-249 de 2003 y sentencia C-228 de 2002, reconoció el derecho a la verdad a las víctimas de violaciones de sus derechos humanos.

En el caso colombiano es importante resaltar, como una parte de la práctica, el reconocimiento que la ley 975 de 2005 (Ley de justicia y paz) hace al derecho a la verdad. Esta ley ha abogado por la conciencia de aceptación de su naturaleza como derecho nacional, lo que conlleva a aportar al reconocimiento como derecho internacional consuetudinario.

Respecto del último requisito referente a la inexistencia de medidas que restrinjan la práctica, habida cuenta de que las comisiones de la verdad son acordes a los derechos humanos reconocidos internacionalmente y en algunos casos considerados como parte del jus cogens, las prácticas que tiendan a proteger el derecho a la verdad no solamente son internacionalmente lícitas, sino que incluso pueden estar protegidas por el derecho internacional.

Por otra parte, si bien en algunos países existen normas de amnistía que prohíben abrir investigaciones sobre ciertos hechos, la jurisprudencia internacional (CRIDH, caso Barrios Altos vs. Perú, 2001) ha determinado con vehemencia la incompatibilidad de esas normas con las obligaciones internacionales de derechos humanos, por lo que no puede entenderse que constituyan restricciones válidas al ejercicio de las prácticas tendientes a consagrar como costumbre el derecho a la verdad. 


\section{Desarrollo jurisprudencial respecto al derecho a la verdad}

En la Corte Interamericana de Derechos Humanos

La Convención Americana de Derechos Humanos no consagra un derecho autónomo a la verdad, lo que implica que la Corte Interamericana de Derechos Humanos no pueda tampoco protegerlo como tal, sin embargo, la Corte en ciertos pronunciamientos declara la vulneración del mismo. Los casos sobre los que ha decido son principalmente el caso Bámaca Velásquez, sentencia del 25 de noviembre de 2000; caso Barrios Altos, sentencia del 14 de marzo de 2001, y caso Castillo Páez, de 1997. En los tres anteriores la Corte, como O’Donnell (2004) afirma:

(...) El derecho a la verdad se encuentra subsumido en el derecho de la víctima o sus familiares a obtener de los órganos competentes del Estado el esclarecimiento de los hechos violatorios y las responsabilidades correspondientes, a través de la investigación y el juzgamiento que previenen los artículos 8 y 25 de la convención.

Atenta contra los artículos 8 y 25 de la Convención Americana de Derechos Humanos, porque violenta la libertad de pensamiento y de expresión, y la protección judicial, ya que al no garantizarse este privilegio se está negando a la persona el derecho a recibir información sobre las circunstancias en las que consistieron el delito.Aunque la Corte no se ha pronunciado de manera reiterada sobre el derecho a la verdad, la Comisión Interamericana de Derechos Humanos sí lo ha realizado varias de veces, mostrando de esta manera la evolución del mismo, ya que afirma que este privilegio surge como la interacción de unas obligaciones y derechos consagrados en el derecho internacional. En el caso García Franco (1997), relacionó el derecho a un recurso al afirmar: 
Este derecho a conocer la verdad sobre lo sucedido se basa también en la necesidad de información que permita reivindicar otro derecho. En el caso de la desaparición de una persona, los familiares tienen derecho a conocer con certeza la suerte corrida por la víctima, no solo para saber exactamente cómo se violaron sus derechos, sino también para hacer efectivo su propio derecho a ser indemnizados por el Estado. Conforme a la legislación, el derecho a una indemnización civil no puede ejercerse sin una determinación judicial de responsabilidad penal.

LaCIDHenel caso "(...) Medina Charry, 1998, vincula el derecho a la verdad con la obligación del Estado a investigar hechos violatorios de los derechos humanos (....)" (O’Donnell, 2004).

En el caso Parada Cea, la CIDH declara que el derecho a la verdad es una obligación del Estado que tiene con los familiares de las víctimas y con la sociedad como consecuencia del derecho a un recurso y del derecho al debido proceso; la CIDH (1999) afirma:

El derecho a la verdad (...) constituye una obligación que el Estado tiene con los familiares de las víctimas y con la sociedad, como consecuencia de las obligaciones y deberes asumidos por dicho país en su calidad de Estado Parte de la Convención Americana sobre Derechos Humanos. Tales obligaciones surgen fundamentalmente de lo dispuesto en los artículos 1(1), 8, 25 y 13 de dicha convención.

En el caso Romero (1995), a manera de síntesis del contenido del derecho a la verdad, la CIDH afirma: 
El derecho que tienen toda persona y la sociedad a conocer la verdad íntegra, completa y pública sobre los hechos ocurridos, sus circunstancias específicas y quiénes participaron en ellos, forma parte del derecho a reparación por violaciones de los derechos humanos, en su modalidad de satisfacción y garantías de no repetición. El derecho de una sociedad a conocer íntegramente su pasado no solo se erige como un modo de reparación y esclarecimiento de los hechos ocurridos, sino que tiene el objeto de prevenir futuras violaciones.

Según O’Donnell (2004), la Comisión Interamericana de Derechos Humanos indica en su jurisprudencia:

(...) Que ni el resarcimiento de los familiares de una víctima ni las investigaciones llevadas a cabo por una comisión que carece de poder sancionatorio cumplen plenamente con el derecho de los familiares a un recurso judicial y con la obligación del Estado de sancionar a los responsables de graves violaciones de los derechos humanos (O'Donnell, 2004).

\section{En la jurisprudencia colombiana}

Actualmente, la Corte Constitucional afirma la existencia del derecho a la verdad, no obstante en un principio este derecho no se consideraba como autónomo, por el contrario, se decía que era un derecho complementario del derecho de libre acceso a la administración de justicia. Se evidencia lo dicho anteriormente con (...) "dos sentencias fundadoras de línea, la T-006 de 1992, M. P. Eduardo 
Cifuentes Muñoz y la T-597 de 1992, M. P. Ciro Angarita Barón" (Quinche Ramírez, 2009). Luego, Quinche Ramírez (2009) afirma "(...) con la sentencia T-275 de 1994 que el derecho a la verdad, radicado en las víctimas y aún sometido hermenéuticamente al derecho de libre acceso a la administración de justicia, comienza a cobrar la autonomía que ostentará definitivamente a partir de 2001".

Por otro lado, la jurisprudencia de la Corte Constitucional, de obligatorio cumplimiento en cuanto interpreta derechos fundamentales (C-053/01), ha establecido respecto del derecho a la verdad que "esta obligación estatal de investigar y sancionar es tanto más intensa cuanto más daño social haya ocasionado el hecho punible.

Por ello ese deber estatal adquiere particular fuerza en los casos de violaciones de derechos humanos" (Corte Constitucional, sentencia C-004/03, 20 de enero de 2003).

La Corte Constitucional por medio de la sentencia C - 454 de 2006, afirma:

El derecho a la verdad.

31. El conjunto de principios para la protección y la promoción de los derechos humanos mediante la lucha contra la impunidad (principios 1 a 4) incorporan en este derecho las siguientes garantías: (i) el derecho inalienable a la verdad; (ii) el deber de recordar; (iii) el derecho de las víctimas a saber. El primero, comporta el derecho de cada pueblo a conocer la verdad acerca de los acontecimientos sucedidos y las circunstancias que llevaron a la perpetración de los crímenes. El segundo, consiste en el conocimiento por un pueblo de la historia de su opresión como parte de su patrimonio, y por ello se deben adoptar medidas adecuadas en aras del deber de recordar que incumbe al Estado. Y el tercero, determina que, indepen- 
dientemente de las acciones que las víctimas, así como sus familiares o allegados puedan entablar ante la justicia, tiene el derecho imprescriptible a conocer la verdad acerca de las circunstancias en que se cometieron las violaciones, y en caso de fallecimiento o desaparición, acerca de la suerte que corrió la víctima.

Esa jurisprudencia ha sido reiterada y ampliada en múltiples ocasiones, en especial en la sentencia C-370/2006, en que la Corte dedica buena parte del examen de la Ley 975 al estudio de su modelo de construcción de verdad, sobre el entendido de que esta última es un derecho de vital importancia para la sociedad.

Por su parte, en la sentencia C- 260 de 2011 vuelve a retomar las garantías de inalienabilidad del derecho a la verdad, el deber de recordar y el derecho de las víctimas a saber. Sin embargo, la Corte en esta sentencia hace referencia que el derecho a la verdad "(...) es la posibilidad de conocer lo que sucedió y en buscar una coincidencia entre la verdad procesal y la verdad real. Este derecho resulta particularmente importante frente a graves violaciones de los derechos humanos" (Corte Constitucional, sentencia C - 260, 2011).

Siguiendo este hilo conductor, existe una línea clara en la Corte Constitucional que tiende a reconocer la autonomía e importancia del derecho a la verdad como un derecho humano autónomo, un verdadero derecho innominado a la luz de la Constitución (artículo 94) que puede servir para ponderar otros derechos de igual naturaleza. Esta evolución se puede verificar en las sentencias T-249/03; C-228/02; C-458/06; C-370/06 y C-260/11.

Por su parte, para la Sala Penal de la Corte Suprema de Justicia (2011), el derecho a la verdad es un derecho: 
(...) Del cual son titulares tanto la víctima como la sociedad, apunta a que se determine de manera precisa y exacta la forma como tuvieron ocurrencia los hechos en general lo cual comprende a sus autores, sus motivos, las prácticas utilizadas, los métodos de financiación, las colaboraciones internacionales estatales o particulares recibidas, a fin de que salga a la luz pública ese acontecer oscuro que debe servir a la comunidad para implementar los correctivos orientados a que no vuelvan a ocurrir tales sucesos, así como establecer dónde se encuentran los secuestrados, los desaparecidos por la fuerza, amén de integrar lo más fidedignamente posible la memoria histórica, y en tal medida asegurar que semejantes conductas no sucedan de nuevo. (Sentencia de Sala penal, 27 de abril de 2011).

Como el derecho a la verdad hace parte de los derechos de las víctimas, en donde las cortes de Colombia lo entienden como el resarcimiento no patrimonial que la víctima tiene derecho a conocer, ya que en un Estado social de derecho la justicia para las víctimas no se obtiene solamente con una compensación pecuniaria, "(...) si no que es necesario que se realicen sus derechos a la verdad y justicia. El primero, en cuanto se determine la naturaleza, condiciones y modo en que ocurrieron los hechos y a que se descubran los responsables de tales conductas" (Corte Suprema de Justicia - Sala Penal, sentencia n. ${ }^{\circ}$ 26703, 6 de marzo de 2008).

\section{Las dimensiones del derecho a la verdad}

Así constituido, el derecho a la verdad puede analizarse desde dos perspectivas distintas o mejor aún, se podría hablar como lo hace Rincón (2010) de las dos dimensiones del derecho a la ver- 
dad. La primera dimensión es aquella que nace de los tratados de Ginebra y se refiere específicamente al derecho que tienen los familiares de una víctima en un conflicto armado. La fuente jurídica normativa de ese derecho es clara (Convenio I de Ginebra, artículo 32, 1949), ha sido reconocida internacionalmente y tiene todos los elementos necesarios para considerarse un verdadero derecho.

Esa dimensión del derecho a verdad ha sido llevada a otros estadios, pero conservando sus elementos fundamentales respecto de la titularidad (en cabeza de los familiares), el contenido de la obligación (lo sucedido con la víctima) y el responsable de la obligación (el actor del conflicto o el Estado). La segunda dimensión del derecho a verdad se relaciona más con la justicia transicional, se refiere al derecho de la sociedad a conocer las causas, modos y consecuencias de una forma generalizada de agresión capaz de causar violaciones sistemáticas y masivas de derechos humanos.

Este segundo concepto de derecho a la verdad tiene mayores problemáticas que el primero, en particular, como ya se explicó, por carecer de un sustento jurídico normativo que evidencie su vigencia, y en segundo lugar, porque a diferencia de la primera dimensión del derecho a la verdad, los elementos estructurales no son claros: por ejemplo, la titularidad del derecho y de la obligación no están bien definidas, así como tampoco está definido con claridad el contenido de la obligación en cuanto a verdad. Frente a este segundo tipo de derecho a la verdad, que tiene que ver mucho más con la sociedad que con el individuo, el desarrollo se ha fundamentado mucho más en la experiencia que en un instrumento jurídico claro.

La forma de satisfacer el derecho a la verdad del segundo tipo se ha visto plasmado fundamentalmente en las denominadas comisiones de la verdad, que se han creado a lo largo del planeta desde 1983, en ejemplos diversos y numerosos que no pare- 
cen regirse por un único modelo, excepto por el de responder a la necesidad de cesar episodios sangrientos de la historia de un país, que bien pudieron darse en el marco de un conflicto armado o simplemente como respuesta a unas violaciones de derechos humanos sistemáticas y generalizadas.

Tan solo en América $12^{5}$ países han tenido comisiones de la verdad, siete de las cuales han tenido repercusiones en el Sistema Interamericano de Derechos Humanos ${ }^{6}$, que ha utilizado sus conclusiones para determinar la responsabilidad de los Estados de la región en ciertas violaciones de derechos que sucedieron en los casos bajo su examen. Según los principios consagrados en los artículos 3 y 4 de la declaración sobre la protección de todas las personas contra las desapariciones forzadas de 1992, el Estado tiene el deber de recordar los archivos y otras pruebas relativas a violaciones de los derechos humanos para así prevenir que surjan tesis negacionistas.

Los mecanismos para garantizarlo, como se mencionó, son las comisiones de la verdad, las cuales deben establecerse de acuerdo con las Naciones Unidas (2006):

(...) De tal forma que queden reflejadas las necesidades, los puntos fuertes y las oportunidades nacionales. Esos procesos consultivos deben tener dos propósitos igualmente importantes: promover

5 Argentina, Bolivia, Brasil, Canadá, Chile, Ecuador, Guatemala, Panamá, Paraguay, Perú, El Salvador y Uruguay.

${ }^{6}$ Chile: Comisión Nacional de Verdad y Reconciliación (1990) y Comisión Nacional sobre Prisión Política y Tortura (2003); Ecuador: Comisión de la Verdad, 2010; El Salvador: Comisión de la Verdad para el Salvador,1993; Guatemala: Comisión para el Esclarecimiento Histórico de las Violaciones a los Derechos Humanos y los hechos de violencia que han causado sufrimientos a la población guatemalteca, 1997; Panamá: Comisión de la Verdad, 2002; Paraguay: Comisión de Verdad y Justicia, 2008; Perú: Comisión de la Verdad y Reconciliación, 2003. 
una mayor comprensión de la labor de la comisión de la verdad y fortalecer su mandato gracias a las aportaciones recibidas sobre el mandato más apropiado. Las consultas deben incluir explícitamente a las comunidades de víctimas y a organizaciones de la sociedad civil, y deben prever un período suficiente para introducir aportaciones importantes al mandato fundamental de la comisión, así como para recibir observaciones sobre los proyectos de mandatos específicos a medida que se vayan elaborando (...).

\section{Esfuerzos en Colombia respecto del derecho a la verdad}

La verdad en algunos países se constituye como parte fundamental de la justicia transicional; ejemplo claro de ello se encuentra en Colombia, que con la Ley de Justicia y Paz pretende brindar verdad, justicia, paz y reparación; lo que para algunos, en lugar de ser benéfico, es perjudicial para la sociedad, ya que todo lo que se cobija por los anteriores objetivos queda en el marco de la impunidad, "estiman que es preferible, en situaciones como la colombiana, enfatizar más en la justicia restaurativa que en la transicional" (Hoyos, 2007). La diferencia entre ambas radica en su fundamento, donde en la primera se entiende que la reparación prevalece sobre cualquier otro elemento, mientras que la segunda, con un fundamento de carácter internacional, busca "justicia con base en la verdad, de la cual se desprendería la reparación y la reforma de las instituciones" (Hoyos, 2007). A partir del año 2005, con la expedición de la Ley 975 del 2005, Colombia empezó una etapa de justicia transicional que a partir de 2010 vendría a complementarse con otras normas (leyes 1424 y 1448).

Según Correa (2007), en Colombia se optó por la verdad judicial para el proceso de reinserción, pero los artículos $7^{\circ}$ y 54 de la 
ley 975 de 2006 dejaron abierta la posibilidad de que se recurra a las comisiones de la verdad y con relación a la tercera esta puede expresarse sin ningún aval de tipo legal. En estas condiciones, la verdad que resulte del proceso de reinserción será pues la convenida, permitida, registrada, en fin, tamizada por el poder.

El problema de la forma de elaboración de la verdad en el proceso de justicia y paz lo señala Alexander González Chavarría (s.f.) en el texto Justicia transicional y reparación a las víctimas en Colombia, donde dice

El acceso de las víctimas a la verdad depende de la disposición de los actores armados ilegales desmovilizados para confesar plenamente y con todo detalle su participación individual o colectiva en actos violatorios de los derechos humanos y del derecho internacional humanitario, lo que constituye de por sí su compromiso fundamental con la justicia colombiana para hacerse acreedores a la pena alternativa en la perspectiva de la justicia transaccional.

Respecto al acceso a la verdad, se presentan tres situaciones problemáticas relevantes. Primero, la anuencia de los desmovilizados a confesar plenamente sus crímenes. En la medida que la capacidad institucional del sistema de justicia se ve desbordada por la magnitud de los procesos en marcha o los crímenes documentados, la veracidad de la confesión depende normalmente de la buena fe del versionado. Los procesos en marcha muestran que este compromiso no se cumple a cabalidad. Segundo, el problema de armonizar, por una parte, las expectativas de las víctimas de conocer la verdad, su necesidad de registrar los hechos, interrogar y contrainterrogar a sus victimarios y, por otra, los requerimientos propios del proceso judicial en el que las versiones libres constituyen una de las primeras etapas de juzgamiento donde se plantean problemas de reserva y confidencialidad de las declaraciones, lo que implica restringir efectivamente la participación de las víctimas. 
Tercero, se tiene la decisión de extraditar a Estados Unidos a los principales jefes paramilitares desmovilizados en julio de 2008. El Consejo Superior de la Judicatura, órgano competente en el tema, consideró que esta decisión no violaba los derechos de las víctimas.

Sin embargo, la extradición de estos cabecillas ha generado un problema importante de coordinación interinstitucional entre la Fiscalía colombiana y las autoridades judiciales en Estados Unidos para desarrollar interrogatorios conjuntos, para lograr la transmisión de las audiencias - de tal forma que las víctimas puedan escuchar los relatos e incluso plantear preguntas a los versionados.

Por último, para dirigir los interrogatorios en función de las necesidades del proceso transaccional, se debate si el proceso se ha desviado y lo importante termina siendo el rasgo particular de narcotraficantes de estos extraditados o si siguen conservando su carácter de actores armados ilegales desmovilizados que entraron bajo ciertas condiciones definidas a un proceso de paz con el gobierno colombiano y con unas obligaciones frente a sus víctimas.

Esto generó, además, una situación jurídica en la que la verdad que se expone dentro del proceso judicial a nivel nacional depende básicamente de la información que manejan los mandos medios y los combatientes rasos de los frentes desmovilizados, dejando de lado la verdad sobre las relaciones estructurales de fondo entre paramilitarismo y sectores políticos y económicos en Colombia.

Por otra parte, como muy bien señala el mismo autor sobre la verdad extrajudicial, este es el complemento de la verdad judicial, pues dice: 
La experiencia internacional muestra que, precisamente frente a las limitantes del proceso judicial como fuente de verdad para las víctimas, las comisiones de la verdad adquieren todo su valor como mecanismo institucional complementario del proceso judicial para lograr cumplir con este requerimiento.

A su vez, la Ley 975 estableció inicialmente la creación de la Comisión Nacional de Reconciliación y Reparación, dentro del cual se creó el grupo de Memoria Histórica, que tiene como objetivo crear los informes sobre los hechos graves de los que se vaya recolectando información.

Así surgieron los informes de Trujillo Una tragedia que no cesa (2008) y El Salado Esa guerra no era nuestra (2009). Dichos informes resultan de una propuesta técnica mucho más adecuada y apegada a los estándares internacionales. Hay interdisciplinariedad en su composición, trabajo de campo y apoyo institucional que se traduce en un informe (el de El Salado) de gran magnitud en cuanto a su difusión e importancia.

Este tipo de documentos resultan de gran importancia, excepto por una falencia: al constituir informes aislados sobre hechos muy puntuales, que no hacen parte de un gran informe, se desarticula el proceso. Las conclusiones de hechos tan precisos resultan muy relevantes para las víctimas y sus familiares, pero desafortunadamente pueden resultar tomándose como ajenas para el resto del país.

Por otra parte, a un nivel más general, la Ley 1424 de 2010, establecida para solucionar el problema jurídico de los más de 31.000 desmovilizados cuya situación jurídica está indefinida, establece un mecanismo no judicial de contribución a la verdad y a la memoria 
histórica. Se trata de generar un medio, acorde con los compromisos internacionales, por el cual los desmovilizados puedan ser indultados.

El problema de esta ley, aún antes de que empiecen a funcionar los sistemas del mecanismo y se pueda evaluar si cumple o no con los estándares en la materia, es que establece en su artículo tercero, parágrafo primero, que "la información que surja en el marco de los acuerdos de que trata este artículo no podrá, en ningún caso, ser utilizada como prueba en un proceso judicial".

Dicha norma deja sin valor alguno el mecanismo, puesto que la verdad no solo debe tener una importancia histórica, sino que justamente debe servir para las investigaciones y no tiene sentido crear una limitante que transgreda las reglas del debido proceso y de la prueba. Una verdad como esta sería una verdad que genera impunidad y eso, lejos de ser el ejercicio de un derecho, es la violación de varios de ellos.

\section{Conclusiones}

1. El derecho a la verdad es un verdadero derecho, cuyo reconocimiento a nivel mundial se fundamenta en la costumbre internacional, constituida porque existe una opinio juris desarrollada a través de principios, declaraciones y jurisprudencia, y consolidada por una práctica que se traduce en la creación de comisiones de la verdad, que tan solo en la región puede verificarse con 12 casos importantes.

2. El derecho a la verdad tiene dos dimensiones claramente establecidas: la primera, de carácter convencional con base en los convenios de Ginebra y las convenciones relativas a desaparición forzada, tiene que ver con los familiares de las vícti- 
mas a conocer la suerte y el paradero de sus familiares. La segunda dimensión es la de la que se refiere al derecho que tiene la sociedad para conocer las causas, modos y consecuencias de los conflictos que generan graves violaciones de derechos humanos. Es un privilegio que surge de la lucha contra la impunidad, tiene el valor de costumbre internacional en virtud de la aceptación de sus rasgos generales y también de la práctica reiterada y uniforme que se ha dado en materia de comisiones de la verdad en el mundo. Este derecho implica, para su satisfacción, un deber a cargo del Estado consistente en construir modelos de comisiones de verdad para lograr la investigación de los hechos y la difusión de los resultados.

3. El contenido del derecho a la verdad está claramente establecido, tanto en los principios de Naciones Unidas como en la jurisprudencia de la CRIDH, por lo que no es posible, actualmente, que un país parte del SIDH pretenda desconocer sus obligaciones al respecto. En el derecho interno, además, la jurisprudencia constitucional ha sido suficientemente clara al respecto.

4. El desarrollo jurisprudencial y doctrinal en Colombia ha dado cuenta de la existencia y reconocimiento del derecho a la verdad como un derecho humano autónomo. En ese sentido, la jurisprudencia constitucional, con valor obligatorio en el derecho interno, se convierte en la fuente de exigibilidad del derecho a nivel interno.

5. Esta obligación interna e internacional implica que el Estado debe adelantar todas las tareas posibles para dar a conocer la verdad, implicando especialmente la creación de comisiones de la verdad con funciones adecuadas a los estándares internacionales en la materia.

6. Los esfuerzos nacionales referentes al derecho a la verdad tienen falencias. El informe de la CVPJ no cumple absoluta- 
mente con ninguno de los requisitos para ser considerado como el cumplimiento del derecho a la verdad de la sociedad. La Ley 1424 de 2010 pretende establecer una herramienta que, lejos de responder al derecho invocado, podría convertirse en un foco de impunidad, contradiciendo de antemano el principal objetivo del derecho a la verdad. Finalmente, el caso de los informes de las masacres de Trujillo y EI Salado dan cuenta de documentos mucho más adaptados a la naturaleza de un informe de comisión de la verdad, sin embargo, se trata de temáticas muy puntuales que no están claramente coordinadas para un informe nacional.

7. Es necesario pensar en un modelo propio de comisión de la verdad que responda a nuestras necesidades, a las características de nuestra sociedad y también a las características del conflicto colombiano. Para eso es necesario que los distintos componentes de la sociedad participen, porque la verdad solo va a ser oída por todos cuando surge de las preguntas de todos. 


\section{Referencias}

Acosta, G.; Valcuende, J.; Gutiérrez, J.; Espinosa, F.; Marroco, M. y Sánchez, J. (2007). La recuperación de la memoria histórica. Una perspectiva transversal desde las ciencias sociales. Consejería de la Presidencia, Centro de Estudios Andaluces.

Alto comisionado de las Naciones Unidas para los Derechos Humanos (2006). Estudio sobre derecho a la verdad.

Alto comisionado de las Naciones Unidas para los Derechos Humanos (2006, 9 de enero). Estudio sobre derecho a la verdad.

Bleeker, M.; Ciurlizza, J.; Bolaños, A. (2008). El legado de la verdad: impacto desde la justicia transicional en la construcción de la democracia en América Latina. Bogotá: Centro internacional para la justicia transicional.

Ciurlizza, J. (2010). Comunicados de prensa. Honduras: nueva comisión de la verdad debe garantizar los derechos de las víctimas.

CNRR (2008). Una tragedia que no cesa. Informe de Trujillo. Recuperado de www. memoriahistorica-cnrr.org.co

CNRR (2009). Esa guerra no era nuestra. Informe de El Salado. Recuperado de www. memoriahistorica-cnrr.org.co

Comisión de Derechos Humanos (2005). El derecho a la verdad. Resolución 2005/66.

Consejería en Proyectos (2009). Los derechos a la verdad, la justicia y la reparación integral. Colombia.

Convención americana sobre derechos humanos (1969). Artículos 1, 8, 13 y 25.

Convención de los derechos del niño. Artículo 8. 
Convenios de Ginebra (1949).

Correa, N. (2007, julio-diciembre). Reinserción y reparación Universitas, 14. Bogotá, Colombia: Pontificia Universidad Javeriana. Recuperado de http://redalyc.uaemex.mx/pdf/825/82511409.pdf

Corte Constitucional de Colombia (2002). Sentencia C-228.

Corte Constitucional de Colombia(2003,20 deenero).SentenciaC-004/03.

Corte Constitucional de Colombia (2003). Sentencia T-249.

Corte Constitucional de Colombia (2003). Sentencia C-004. Recuperado el 16 de abril de 2011 desde http://www.corteconstitucional.gov.co/relatoria/

Corte Constitucional de Colombia (2006). Sentencia C-370. Recuperado el 25 de abril del 2011 desde http://www.corteconstitucional.gov.co/relatoria

Corte Interamericana de Derechos Humanos (1987,26 de junio). Caso Velásquez Rodríguez vs. Honduras. Sentencia de 26 de junio de 1987.

Corte Interamericana de Derechos Humanos (2001, marzo). Caso Barrios Altos vs. Perú. Sentencia de 14 de marzo de 2001.

Corte Interamericana de Derechos Humanos. (2001). Caso Barrios altos vs. Perú.

Corte Interamericana de Derechos Humanos (2002). Caso Bámaca Velásquez vs. Guatemala.

Corte Interamericanade Derechos Humanos.(2003). Caso Buliciovs Argentina.

Corte Interamericana de Derechos Humanos (2010, 26 de mayo). Caso Manuel Cepeda Vargas vs. Colombia. Sentencia de 26 de mayo de 2010. 
CVPJ. (2009) Informe final. Recuperado de: http://www.verdadpalacio.org.co/

Espinoza, B. (s.f.). Derecho a la verdad: antídoto al veneno de la impunidad. Recuperado el 5 de agosto de 2011 desde https:// es.scribd.com/document/249207404/Derecho-a-La-Verdad

Freeman, M. (s.f.). Director del Centro Internacional para la Justicia Transicional (ICTJ) en Bruselas. África y sus comisiones de la verdad y reconciliación. Revista Hechos del callejón, edición especial, 21. (Consultado el 22 de octubre de 2011). Recuperado de http://www.acnur.org/pais/docs/1720_2.pdf?view=1.

Gamboa (s.f.). Justicia transicional: teoría y praxis. Editorial Universidad del Rosario.

Gómez, M. (2009). Comisiones de verdad: ¿qué tanto aportan a la verdad, la justicia y la reconciliación. Colombia: Ed. Red Oasis.

González Chavarrí, A. (2010). Justicia transicional y reparación a las víctimas en Colombia. Revista mexicana de sociología, 72 (4).

González, D. (2008). El derecho a la verdad en situaciones de postconflicto bélico de carácter no internacional. Revista International Law.

Hayner, P. (2006). Instrumentos del Estado de derecho para las sociedades que han salido de un conflicto. Comisiones de la verdad. Naciones Unidas, Nueva York y Ginebra.

Hernández, E. (2006). Los significados de la reconciliación desde las voces de las víctimas. México: Ed. Red convergencias.

Hoyos, G. (2007). Las víctimas frente a la búsqueda de la verdad y la reparación en Colombia. Bogotá: Ed. Pontificia Universidad Javeriana. 
ICRC (2005). Rule 117, Customary International Humanitarian Law, volume I, Rules, Cambridge Press University, p. 421.

Jaramillo, J. (2010). Reflexiones sobre los "usos" y "abusos" de la verdad, la justicia y la reparación en el proceso de justicia y paz colombiano. Colombia: Papel político.

Joinet, M. (1997). Informe de la Comisión de Derechos Humanos. La cuestión de la impunidad de los autores de violaciones de los derechos humanos (civiles y políticos). ONU.

Joinet, M. (1997, 12 de octubre). La administración de la justicia y los derechos humanos de los detenidos. La cuestión de la impunidad de los autores de violaciones de los derechos humanos (civiles y politicos). Informe final de la Comisión de Derechos Humanos - ONU, elaborado y revisado por aplicación de la decisión 1996/119 de la Subcomisión. Distrito General E/CN. 4/Sub. 2/1997/20/

Joinet, M. (2005). Conjunto de principios para la protección y la promoción de los derechos humanos mediante la lucha contra la impunidad. ONU $61^{\circ}$ periodo de sesiones.

Ley 1424 (2010). Colombia.

Ley 975 (2005). Ley de Justicia y Paz. Colombia.

Lira, E. (2010). Trauma, duelo, reparación y memoria. Revista de estudios sociales. Bogotá.

Méndez, J. E. (1998, septiembre). The Right to Truth, en Christopher C. Joyner (ed.), Reining in Impunity for International Crimes and Serious Violations of Fundamental Human Rights: Proceedings of the Siracusa Conference, 17-21, September 1998, St. Agnes, Erès.

Naqvi, J. (2006). El derecho a la verdad, ¿realidad o ficción? Inter- 
national Red Cross Review, 862.

Newman-Pont, V. (2009). Falso o verdadero (¿El derecho a la verdad es norma imperativa internacional?), Internacional Law, 14, pp. 43-69.

Peace Agreement between the Government of Sierra Leone and the Revolutionary United Front of Sierra Leone (art. XXVI) and the Government of Chile Supreme Decree n. ${ }^{\circ} 35$ of 25 April 1990, establishing the Truth and Reconciliation Commission.

PIDCP (s.f.). Artículos 7 y 23.

Reaño, M. (s.f.). El derecho a la verdad. Pontificia Universidad Católica del Perú.

Relator especial sobre los derechos humanos y los Estados de excepción (s.f.) $8^{\circ}$ informe anual: documento de la ONU E/CN.4/ Sub.2/1995/29 Corr. 1

Resolución 2005/66 de la Comisión de Derechos Humanos. Recuperado el 8 de marzo de 20011 desde http://www.acnur. org/secciones/index.php?viewCat=267

Rincón, T. (2009). La verdad histórica: una verdad que se establece y legitima desde el punto de vista de las víctimas. Colombia: Red revistas estudios socio-jurídicos.

Rincón, T. (2010) Verdad, justicia y reparación. Los derechos a la verdad y a la justicia, p. 45. Bogotá: Universidad del Rosario.

Rincón, T. (2010) La justicia de la justicia transicional. Editorial Universidad del Rosario.

Stiglitz, J. (2007). The right to know; transparency for an open world. Columbia University Press. 